\title{
Pentingnya Self Awareness Kesehatan Mental dan Growth Individu di Masyarakat
}

\author{
Alya Azra Ananda Nuril \\ S1 Psikologi Fakultas Kedokteran Universitas Lambung Mangkurat \\ alyazraulm@gmail.com
}

\begin{abstract}
Abstrak. Banyak sekali distraksi kehidupan yang membuat kita lupa akan pentingnya kesehatan mental dan pentingnya berproses. Distraksi dari lingkungan menghasilkan penuntutan yang tidak berhenti di diri kita yang secara bersamaan membuat kita melupakan bahwa selain hasil kita juga sambil berproses menjadi manusia. Metode jurnal ini adalah metode kajian literatur. Penulis menulis jurnal ini bukan bertujuan agar mengajak pembaca melihat di aspek berproses saja dan melupakan hasil, melainkan mengajak pembaca menuju kesadaran bahwa kurangnya masyarakat sekarang untuk menghargai beproses dirinya dan orang lain. Regulasi emosi sangatlah penting untuk menangani stress dari penuntutan lingkungan dan diri kita sendiri.
\end{abstract}

Kata Kunci : Lingkungan, Kehidupan, Individu, Manusia, Stress, Emosi, Distraksi

\section{PENDAHULUAN}

Agama dan budaya adalah faktor dan struktur utama dalam perubahan kehidupan sosial dan politik. Banyaknya perbedaan moral, arti kehidupan, dan tujuan eksistensi di dunia, menghasilkan banyaknya perspektif "bermacam kebenaran" mengenai tujuan eksistensi kehidupan. Sudah tidak asing lagi bagi kita jika perbedaan kepercayaan antar manusia bisa menghasilkan banyak nya konflik kecil sampai konflik besar seperti contohnya "peperangan". Mengapa demikian? mengapa perbedaan menghasilkan banyak kerusakan dan korban-korban yang tidak bersalah? Hal tersebut dikarenakan lack of understanding dari individu dan kelompok atas keterbukaan dengan kepercayaan dan moral manusia lain. Ada juga kurangnya empati dan keegoisan yang menyebabkan tingkah laku yang bisa merugikan orang lain, bahkan secara masif. Selain perbedaan di dunia secara general, bisa kita rasakan permasalahan yang semakin melonjak di masyarakat, apalagi pada kaum muda sekarang yaitu insecurity dan adanya ketidaksadaraan masyarakat dalam mementingkan berproses dirinya dan orang lain sebagai manusia yang selalu berkembang.

Kita semua pasti pernah mendengar quotes ini berulang-ulang kali "Kita semua adalah makhluk tuhan. Tidak ada yang sempurna, hanya Tuhan yang memiliki kesempurnaan". Tentu saja hal tersebut benar, akan tetapi penulis banyak menemukan individu yang menggunakan quotes ini hanya sebagai pelindung atau perisai sifat manusiawinya. Apa yang penulis maksud dengan sebagai "perisai manusiawinya"? bukankah quotes tersebut bertujuan agar kita bisa memandang individu tersebut sebagai "makhluk yang 
selalu membuat kesalahan yang tidak disengaja". Kenyataannya tidak, kebanyakan orang memakai quotes ini hanya untuk melindungi dirinya sendiri dari kesalahan, dan sayangnya bukan sebagai bentuk normalisasi untuk berkembang. Manusia yang manusiawi, manusia yang memiliki potensi adalah manusia yang belajar dari kesalahannya dan menerima bahwa dia tidak akan selalu benar. Lucunya beberapa orang akan menggunakan quotes ini kepada dirinya, tetapi jika melihat orang lain melakukan kesalahan, mereka tidak menggunakan prinsip quotes tersebut kepada orang itu. Bisa disimpulkan contoh skenario tersebut menunjukkan ketidaksadaraan individu tersebut dan menjustifikasikan perilaku yang harus nya bisa di regulasi. Mengapa demikian? kenapa kita memiliki ketakutan menghadapi kesalahan kita dan sisi buruk kita? Karena pandangan kita selalu di luar, dunia eksternal. Kita melakukan bermacam aktivitas dan menghabiskan energi kita setiap harinya agar memenuhi kebutuhan tujuan primer maupun sekunder untuk lingkungan kita dan diri kita. Setiap individu membutuhkan afeksi dan validitas dari orang sekitar sebagai bentuk arah. Manusia membutuhkan arah untuk hidup, dan kebanyakan manusia menginginkan arah dimana manusia tersebut merasa bahwa eksistensi nya berharga dan bermanfaat. Karena mengejar arah melalui validitas, kita lupa akan pentingnya menjaga mental health dan melakukan self assessment di diri kita. Society dibangun untuk selalu bekerja dan menyuruh kita agar bisa meng-oqtimalkan diri untuk environment yang baik. Akan tetapi, sayang sekali, masyarakat sekarang lebih berfokus kepada dunia eksternal sebagai bentuk fulfilling hidup dirinya tersebut. Padahal ilmu psikologi merupakan akar dari permasalahan individu tersebut dan masalah sosial yang sekarang banyak sekali terjadi. Banyaknya distraksi dari lingkungan, menghasilkan penuntutan yang tidak berhenti di diri kita yang secara bersamaan membuat kita melupakan bahwa selain hasil kita juga sambil berproses menjadi manusia.

Interaksi antara manusia dengan lingkungan hidup dapat memicu timbulnya berbagai permasalahan lingkungan (M. Abdan Shadiqi, Hemy Heryati Anward, Neka Erlyani, 2013)

Penuntutan yang banyak, membuat kebanyakan dari kita akan mengalami burn out dan perasaan overwhelmed sehingga muncul emosional stress. Apalagi di fase pandemi dan perkuliahan saat ini, dimana kita berada di fase ketidaktentuan dan secara bersamaan penuntutan kuliah yang lumayan banyak dan berat. Kehidupan memang keras, tetapi jika kita melupakan aspek penting ini (berproses), percuma, sama saja kita melupakan diri kita, identitas diri kita. Menurut bu Eka Puspita Dewi, Tuntutan tugas akademik yang adakalanya dirasakan berat oleh mahasiswa, adakalanya di luar kemampuan mahasiswa, alih-alih membantu menjaga kesehatan mental, tetapi sebaliknya, meningkatnya stres mahasiswa selama "karantina" di rumah. Sepertinya bagi mahasiswa persepsi untuk menjaga diri karena dunia sedang sakit tidak cukup untuk mengatasi kekhawatiran di tengah pandemi seperti sekarang. Sekalipun demikian, pada ketika seperti inilah ujian ketahanan mental mahasiswa mendapat cobaan (Eka Puspita Dewi, 2020). Tentu saja kita sebagai individu harus memainkan peran agar lingkungan dan masyarakat bisa terjalankan dengan baik, jika bukan kita, siapa lagi? Menurut bu Mutiani, setiap masyarakat majemuk di era modern selalu mempersiapkan warganya untuk 
kepentingan kelanjutan (regenerasi) setiap komunitas di belahan bumi manapun (Mutiani, 2017). Tentunya tidak ragu dan tidak salah jika kita menuntut kesempurnaan. Karena hidup bukan sekedar hidup, tetapi hidup yang bermakna, dengan demikian, aktivitas kehidupan harus didayung. (Eka Puspita Dewi, 2020). Tetapi perlu diingat ada tempat dan limit untuk menuntut kesempurnaan terhadap orang lain dan tentunya diri sendiri.

Semua orang memiliki perbedaan pandangan tentang bagaimana menjalani kehidupan yang baik. Akan tetapi pernahkah kita bertanya kehidupan macam apa yang layak kita pertahankan selama berada di dunia ini. Banyak sekali distraksi kehidupan yang membuat kita mau tidak mau "harus peduli". Kita semua mengikuti perkembangan arus yang cepat. Tetapi bagaimana jika kita tidak memenuhi dan mengikuti standar dan arus tersebut?stress dan merasa insecure adalah salah satu contoh dari hal tersebut. Kita ingin kaya, kita ingin sukses, kita ingin dipuji oleh banyak kalangan individu, dan ketika semua itu tidak terpenuhi dan hilang, kita kehilangan diri kita dengan kehampaan.

Pada era globalisasi ini bisa kita lihat bagaimana kehidupan berubah secara drastis dikarenakan media sosial. Media sosial memiliki keuntungan sendirinya tentunya, tapi marilah jujur, media sosial banyak membawa dampak negatif untuk kepribadian kita dan mental being kita. Perasaan ingin diakui, perasaan ingin lebih, dan perasaan rendah diri karena media sosial membuat kita bertanya- tanya atas kemampuan kita, merasa ada yang salah dalam kehidupan kita, dan terakhir mempertanyakan keadilan dari tuhan.
Hidup itu adil, tergantung oleh apa yang kita fokuskan dan apa yang kita pikir sebagai "hidup yang adil". Misal kita mungkin saja merasa iri dikarenakan melihat betapa untungnya seseorang yang mendapatkan validasi oleh orang-orang disekitarnya dikarenakan orang itu attractive secara fisik, dan hal itu membuat kita berpikir, ternyata "ahh, hidup ternyata tidak adil". Jika kita telaah dan pikirkan dengan baik-baik, kita semua mengalami kehidupan pahitnya masing-masing. Hidup itu kompleks dan penuh makna,. Setiap individu mempunyai makna nya masingmasing. Semakin kita selalu menginginkan validasi, afirmasi baik oleh orang lain, kita menutup potensi kita untuk berkembang untuk menjadi manusia yang berkualitas. Ada orang yang menghadapi masalah ekonomi, ada yang merasa insecure, ada yang mengalami depresi, ada yang kehilangan orang yang disayangi nya, ada yang menghadapi masalah ego nya sendiri, kehidupan dan individu yang bermacammacam. Penulis menulis jurnal ini bukan bertujuan agar mengajak pembaca melihat di aspek berproses saja dan melupakan hasil, melainkan mengajak pembaca menuju kesadaran bahwa kurangnya masyarakat sekarang untuk menghargai proses kehidupan yang harus diprioritaskan dirinya dan orang lain. Kita boleh menginginkan kesempurnaan dan keefektifan hasil dari kerja kita atau yang orang peroleh ,tapi jangan lupa ada usaha, pengorbanan, penderitaan, lelah di balik itu.

\section{METODE}

Metode jurnal yang dipakai di jurnal ini adalah metode kajian literatur yang terinspirasi dari buku karyanya Mark Manson, berjudul The Subtle Art Of Not 
Giving a $F^{*}$ ck. Buku ini adalah buku self help, yang sangat sukses dan mendunia. Buku ini membahas tentang seni bersikap tidak peduli. yang dimaksud buku ini bukan tidak peduli secara totalitas, melainkan memprioritaskan diri terhadap hal yang penting daripada hal yang membuat kita terhambat dalam berproses diri menjadi manusia. Selain buku The Subtle Art Of Not Giving a F*ck, penulis melaraskan dan mengutip berbagai jurnal dan buku yang berhubungan dengan topik jurnal agar informasi yang didapatkan bisa relevan dan jelas. Kebanyakan jurnal diambil dari jurnal dosen-dosen Program Studi Psikologi, Fakultas Kedokteran, Universitas Lambung Mangkurat, sebagai bahan referensi dan juga pelengkap pengutipan.

\section{HASIL DAN DISKUSI}

Bagaimana seharusnya kita sebagai manusia memandang dunia? Apakah setengah gelas penuh atau setengah gelas kosong? tentunya keduanya. Kita seharusnya bukan melihat dari satu pandangan saja, tetapi bisa mengidentifikasikan bahwa kedua pandangan tersebut benar. Susah sebenarnya melihat dunia dengan kedua pandangan tersebut secara bersamaan. Ketika kita merasa bahagia, sepertinya kita akan lupa dengan permasalahan yang kita punya, bahkan bisa lupa jika kemudian nanti kita akan menghadapi permasalahan yang lainnya. Tetapi bisa kita temui banyak orang-orang yang aware akan melonjak naik turunnya kehidupan. Orang-orang seperti ini melihat kehidupan secara "realitas" tetapi mempercayai dengan ide perubahan. Cara pandang tidak bisa dihasilkan begitu saja, butuh banyaknya reminder diri dan edukasi seperti mental awareness, dan yang terutama, yang tidak luput adalah pengalaman kehidupan.

Pembangunan manusia pada dasarnya adalah kegiatan yang terletak secara sosial di mana eksplorasi informasi untuk membangun pengetahuan dan berinteraksi dengan individu lain sangat penting. Karena memberikan dampak positif pada pertumbuhan manusia (Jumariati, Gunadi Harry Sulistyo, 2017).

Kehidupan keras. Bisa kita rasakan secara perlahan bahwa dunia tidak bisa lagi dilihat dengan kacamata berwarna-warni. Kita harus melihat dunia berdasarkan apa yang ada, dan merasakannya. Perkembangan diri dan kesuksesan biasa muncul bersamaan, tapi kedua hal tersebut berbeda makna tentunya, bisa kita rasakan budaya sosial sekarang terobsesi dengan ekspektasi tidak realita yang berlandaskan kesenangan. Respon pribadi terhadap tugas perkembangan individu dan serta tuntutan kebutuhan pada saat ini berbeda-beda, sehingga tidak semua orang mampu mengatasi tantangan perkembangan. Individu yang mempersiapkan dirinya dengan baik dalam perubahan akan melewatinya dan siap untuk menjadi individu yang dewasa, sedangkan individu yang merasa kesulitan melihat periode perubahan perkembangan nya sebagai masa yang sulit dan penuh kegelisahan sehingga individu merasa belum bisa mengatasi tantangan dan perubahan yang terjadi di hidupnya. Permasalahan tersebut konsisten menghasilkan reaksi dan krisis negatif emosi yang terjadi dalam diri individu seperti ketidakberdayaan, isolasi, ketakutan untuk diragukan, dan ketakutan atas kegagalan yang telah disebutkan (Afnan, Rahmi Fauzia, Meydisa Utami Tanau 2020). 
Perlu diketahui tidak mudah untuk mendapatkan self aware yang optimal. Mengenal diri adalah pelajaran seumur hidup yang penuh perjuangan. Maka dari itu pertama-tama kita harus memahami bahwa edukasi mental sangatlah penting untuk memahami diri sendiri, individu, kelompok, dan masyarakat secara general.

Pendampingan psikologi diberikan oleh ahli psikologi sebagai upaya membantu meningkatkan kondisi individu agar dapat memenuhi kebutuhan hidup untuk berarti, mempunyai rasa aman, kebutuhan untuk dicintai dan respek, harga diri, dan dapat membuat keputusan dan aktualisasi diri (Duwi Nur Hafifah, Silvia Kristanti Tri Febriana, Rahmi Fauzia, 2016).

Kerentanan, banyak individu yang bisa kita temukan, tidak menghargai kerentanan, menganggap bahwa menunjukkan emosi adalah sebuah kelemahan dan hanya mengganggu apa yang ada dihadapan kita. Jika menginginkan kehidupan tanpa kerentanan, coba bayangkan kehidupan tanpa emosi, tidak tertawa bahagia, menangis bahagia, menangis karena sedih, marah, dan yang parah, tidak ada perasaan sedih jika orang yang kita sayangi meninggal, apakah terlalu jauh? Emosi merupakan sebuah hadiah dan juga kutukan kehidupan, tergantung, kita semua mempunyainya dan jika berusaha menghilangkannya sama saja menghina Tuhan. Hal ini bukan berarti kita meminta orang lain untuk memahami emosi kita, tentunya ada batasannya.

Kita yang mempunyai pikiran, kita yang mempunyai perasaan, kita yang mempunyai diri, kalau tidak kita yang memanage, ya siapa lagi? Orang lain, termasuk psikolog, mampu memberi nasehat, tetapi bukankah kita yang melaksanakannya?Mempraktikkan

ketangguhan psikologi, terutama pada saat kita berkesulitan. Ingat: Setiap orang bertanggung jawab atas dirinya. (Ersis Warmansyah Abbas, 2020)

Tidak semua emosi negatif menghasilkan kepribadian yang buruk, kita semua tahu, kepahitan kehidupan yang membuat diri kita menjadi pribadi yang lebih baik, dan sekali lagi tergantung bagaimana diri kita meregulasi semua itu sebagai pelajaran. Semua ini tentunya berlaku kepada orang lain, kita tidak bisa menyamakan value diri kita dengan orang lain, kita tidak bisa asal memarahi orang sebagai ketegasan, karena kita tidak tahu sepenuhnya bagaimana kondisi individu tersebut, kita bahkan tidak tau diri kita sepenuhnya, tapi bukan berarti manusia tidak memiliki pertanggungjawaban, kitalah yang bertanggung jawab atas diri kita sendiri, manusia pasti selalu salah, daripada selalu menghakimi, lebih baik mengedukasi dan saling mengarahkan, karena seberapa gigihnya kita memperbaiki human error, cara memperbaiki individu berbeda-beda. Di banyak keributan, kebencian, dan pertentangan manusia, sepertinya kita lupa bahwa keberadaan kita bukan hanya keberadaan di diri kita, tapi puluhan puluhan orang. Rasakan keberadaan diri kita diantara orang-orang yang kita sayangi, keluarga dan teman-teman yang bahagia melihat keberadaan kita di sekitarnya, seorang yang kita tidak kenal tiba-tiba tertawa dengan candaan kita. Semua ini, merupakan keindahan dari hidup, manusia ke manusia lain, mempengaruhi sesama lain.

Bapak memegang bagian dada saya lalu melambungkan ke udara dan kedua tangan Beliau menyambut sembari tertawa. Duh, 
senangnya. Hal tersebut ditulis di otak dengan baik dan benar (Ersis Warmansyah Abbas, 2020).

\section{KESIMPULAN}

Proses diri merupakan perjalanan seumur hidup yang melelahkan, perlu kita sadari, bukan orang lain lah yang bertanggung jawab atas proses diri kita, melainkan diri kita sendiri, tetapi perlu dipahami juga bahwa kita mempunyai limit kita masingmasing, begitu pula orang lain. Banyaknya distraksi sosial yang tinggi membuat diri kita kesusahan untuk memenuhi kebutuhan sekunder dan primer kita sehari-hari, dan yang paling penting yaitu proses dan kesehatan mental kita. Perlahan-lahan bisa kita rasakan, kehidupan tidak bisa lagi dilihat dengan kacamata berwarna. Kenyataan adalah kenyataan. Mungkin susah untuk mendorong masyarakat untuk peduli kepada kesehatan mentalnya, mungkin semuanya terlihat tidak mungkin, tapi dari kita lah, kita yang aware akan permasalahan yang ada, berusaha mengedukasi masyarakat sesuai kemampuan.

\section{REFERENSI}

Shadiqi, M. A., Anward, H. H., \& Erlyani, N. (2013). Hubungan Antara Kecerdasan Emosional dengan Perilaku Pro-Lingkungan Serta Perbedaannya berdasarkan Jenis Kelamin. Ecopsy, 1(1), 195923.

Mutiani, M. (2017, November). Education and multiculturalism: The road ahead harmony in globalization. In 1st International Conference on Social Sciences Education-" Multicultural Transformation in Education, Social Sciences and Wetland Environment"(ICSSE 2017). Atlantis Press.

Abbas, E. W., \& Erlyani, N. (2020). Menulis di Kala Badai Covid-19.

Jumariati, J., \& Sulistyo, G. H. (2017). Problem- based writing instruction: Its effect on students' skills in argumentative writing. Arab World English Journal (AWEJ) Volume, 8.

Afnan, A., Fauzia, R., \& Tanau, M. U. (2020). HUBUNGAN EFIKASI DIRI DENGAN STRESS PADA MAHASISWA YANG BERADA DALAM FASE QUARTER LIFE CRISIS. Jurnal Kognisia: Jurnal Mahasiswa Psikologi Online, 3(1), 2329

Hafifah, D. N., Febriana, S. K. T., \& Fauzia, R. (2016). Efektivitas Pendampingan Psikologi dengan Metode Appreciative Inquiry untuk Meningkatkan Kepercayaan Diri. Jurnal Ecopsy, 2(3).

Abbas, E. W. (2020). Menulis Mudah, Menulis Ala Ersis Writing Theory. 